\title{
Electrophoretic Study of Binary and Mixed Metal Complexes with Medicinally Important Ligands
}

\author{
Arvind Singh ${ }^{1,2}$, Siddharth Kumar Verma ${ }^{1,3}$ Arvind Prasad Dwivedi ${ }^{4}$ and O.P. Rai ${ }^{1}$ \\ ${ }^{I}$ Department of Chemistry, Govt. (Autonomous) P.G. College, Satna-485001 (M.P.) India \\ ${ }^{2}$ Department of Chemistry Govt. Chandrya Vijay College, Dindori-481880 (M.P.) India. \\ ${ }^{3}$ Department of Chemistry Govt. College Semariya, Rewa-486445 (M.P.) India. \\ ${ }^{4}$ Department of Chemisrty, Govt. Sanjay Gandhi Smrati Auto. P.G.College, Sidhi M.P.
}

\author{
*Corresponding Author: Arvind Singh, Department of Chemistry Govt. Chandrya Vijay College, \\ Dindori-481880 (M.P.) India
}

\begin{abstract}
Metals occur naturally in the earth's crust and their contents in the environment can vary between different regions resulting in spatial variations of background concentrations. Human health is closely linked with a healthy and clean environment. Rapid growth in urbanization and industrialization has increased the levels of heavy metals in the environment and consequently in the food chain. Metal ions are required for many critical functions, physiological and pathological process in human. Iron and Manganese are essential micronutrients with a variety of biochemical functions in all living organism and their lethal dose become toxic to human body. High concentration of metal ions in living system can be prevented by the use of specific chelating agents. The complexation of $\mathrm{Fe}(\mathrm{III})$ and $\mathrm{Mn}(\mathrm{II})$ with medicinally important ligand ephedrine and NTA in solution were studied by paper electrophoretic technique. Stability constants of investigated chelates were determined at $25^{\circ} \mathrm{C}$. The stability constant data revealed that ephedrine and NTA may be used as chelating agent.
\end{abstract}

Keywords: Entity, Metal, complexes, electrophoresis, Chelation, Stability constants.

\section{INTRODUCTION}

Human health is closely linked with a healthy and clean environment. Rapid growth in urbanization and industrialization has increased the levels of heavy metals in the environment and consequently in the food chain. Metals ions play an important role in biological system ${ }^{\mathbf{1 - 3}}$ and required for many critical functions in human. Metal coordination to medicinally active molecules can be used to enhance their activity. The chemistry of metal-drug coordination compounds is more popular now than before particularly in the design of more biologically active drugs. ${ }^{4}$ Many drugs posses modified pharmacological and toxicological properties when administered in the form of metallic complexes. The efficacies of the drug on coordination with a metal are enhanced in many cases. ${ }^{5}$ Iron and Manganese are essential micronutrients with a variety of biochemical functions in all living organism. The amount of these metals can be varying in human body through intake of diet and different environmental factors, either contribute cause toxicity. ${ }^{6}$ The present paper describes a paper electrophoretic method for the determination of stability constant of biologically significant metal complexes in solution. Stability constant is useful physical entity, which explains the importance and function of various complexes in biological systems. ${ }^{7-9}$ High concentration of metal ions in living system can be prevented by the use of specific chelating agents. The chelation therapy for intoxication of metals depends upon the chelating agent being able to reach the intercellular site where the metals are firmly bound. For a pretty long time, varieties of ligand have been used as chelating agent to combat metal poisoning. In present study, ephedrine has been used as primary ligand, which is a sympathomimetic ammine commonly used as a stimulant, appetite suppressant, concentration aid, decongestant and treat hypotension associated with anaesthesia. Literature survey ${ }^{10-16}$ reveals that no work has been reported using ephedrine as a primary and NTA as a secondary ligand till now. This inspired us to study the stability constant of binary and mixed complexes of ephedrine and NTA with Fe (III) and Mn (II) in solution using paper electrophoretic technique. 


\section{Materials AND MethodS}

$\mathrm{Fe}(\mathrm{II}))$ and $\mathrm{Mn}$ (II) perchlorates were prepared by precipitating the corresponding carbonates from 0.1 M solutions of chloride (A.R. grade) with the solution of sodium carbonate, washing the precipitates thoroughly with boiling water and dissolving in a suitable amount of $1 \%$ perchloric acid. The resulting solutions were heated to boiling on a water bath and then filtered. ${ }^{9}$ The solutions were standardized and diluted with distilled water. As required A. R./BDH grade ephedrine, $\mathrm{NaOH}$, $\mathrm{HC}_{10}$, NTA and specific colour developing reagents were used for different metal ions of binary and ternary system sets for specific colour development. Ammonium thiocyanate for $\mathrm{Fe}(\mathrm{III})$ and $0.1 \%$ (W/V) solution of 1-(2- pyridylazo)-2-naphthol (PAN) in ethanol for Mn(II) was used. A saturated aqueous solution $(0.9 \mathrm{ml})$ of silver nitrate was diluted with acetone to $20 \mathrm{ml}$. Glucose was detected by spraying with this solution and then with $2 \%$ ethanolic sodium hydroxide, forming a black spot.

Stock solution of $(5.0 \mathrm{M})$ was prepared by suitable dilution of $70 \%$ perchloric acid (SDS A. R. grade). 2.0 M sodium hydroxide (A. R. grade) and $0.5 \mathrm{M}$ stock solutions of the complexing reagent alizarin and NTA (A. R. grade) solutions were prepared. All chemicals were used without further purifications. Each solution was standardized using the appropriate method. The background electrolyte used in the study of binary complexes was $0.1 \mathrm{M}$ perchloric acid and $0.01 \mathrm{M}$ ephedrine. For the study of mixed systems the background electrolyte used consisted of $0.1 \mathrm{M}$ perchloric acid, $0.01 \mathrm{M}$ ephedrine and varying amounts of $0.01 \mathrm{M}$ NTA. The system was maintained at various pHs by the addition of sodium hydroxide.

Strips of Whatman No. 1 filter paper for chromatography $(30 \times 1) \mathrm{cm}^{2}$ were used and the potential gradient was $6.6 \mathrm{~V} / \mathrm{cm}$.

A Systronic (Naroda, India) Model 610 electrophoresis system was used. The apparatus consisted of a PVC molded double tank vessel. It has a built-in power supply (a.c.-d.c.) that is fed directly to a paper electrophoresis tank. In our laboratory significant change in the instrument has been made. Two hollow rectangular metallic plates coated with thin polyethylene sheets on the outer surface have been used through which thermo stated water is run for controlling the temperature $\left(25^{\circ} \mathrm{C}\right)$. The tanks were closed with a transparent PVC molded lid. The whole assembly is tight which prevent moisture changes, which may upset the equilibria in a paper strip. The assembly design keeps to a minimum the disturbing effects of evaporation from the unwanted liquid flow in the paper. Each electrolyte tank contains a separate electrode chamber in which the anode and cathode are placed, respectively. The $\mathrm{pH}$ measurements were made with an Elico (Hyderabad, India) Model $\mathrm{L}_{1^{-}} \mathrm{O} \mathrm{pH}$ meter using a glass and calomel electrodes assembly, working on $220 \mathrm{~V} / 50 \mathrm{~Hz}$ established a.c. mains.

The midpoint of each Whatman filter paper strip was marked for recording the mobility observation of a particular metal ion. Each of the two electrolyte vessels was filled with $150 \mathrm{ml}$ of background electrolyte containing $0.1 \mathrm{M}$ perchloric acid and liganding reagent $\left(1.0 \times 10^{-2} \mathrm{M}\right)$. The paper becomes moistened with the background electrolyte solution due to diffusion. Then the spot of each metal solution was applied at the marked mid-point of the strips using micropipette. At least one strip was spotted with glucose solution for electro-osmotic correction. The second insulated plate was placed on the paper strips and then thermo stated water $\left(25^{\circ} \mathrm{C}\right)$ was circulated in the plates to keep the temperature constant. The lid was, then, placed on the instrument to make it air tight. It was left for 10 minutes to insure wetting of paper strips. Subsequently, a direct 200 volts was applied between the electrodes. Eletrophoresis was carried out for 30 minutes after which these strips were removed from the tank and dried. The metal ions and glucose spots were detected by specific reagents. The leading and tailing edges were measured from the mid-point and the mean were taken. The distance moved by glucose spot was subtracted (in case of migration towards anode) to obtain the correct path length. Migration towards anode and cathode were designated by negative and positive signs, respectively.

Electrophoretic observations on metal ion spots were recorded at various $\mathrm{pH}$ values of the background electrolyte obtained by adding sodium hydroxide solution, the ionic strength being maintained at O.I M. The observed mobility of the migrant was calculated by using the equation (1)

$$
\mathrm{U}=\frac{\mathrm{d}}{\mathrm{x} \cdot \mathrm{t}}
$$

After applying the correction factor, the observed mobility is given as in equation (2). 


$$
\mathrm{U}=\frac{\mathrm{d} \pm \mathrm{d}_{\mathrm{G}}}{\mathrm{X} \cdot \mathrm{t}}
$$

Where $\mathrm{U}=$ mobility of metal ion/complex ion, $\mathrm{d}=$ mean of duplicate distances travelled by metal ion/complex ion, $\mathrm{d}_{\mathrm{G}}=$ mean of duplicate distances travelled by glucose spots, $\mathrm{x}=$ field strength and $\mathrm{t}$ $=$ time for electrophoresis.

\section{RESULTS AND DISCUSSION}

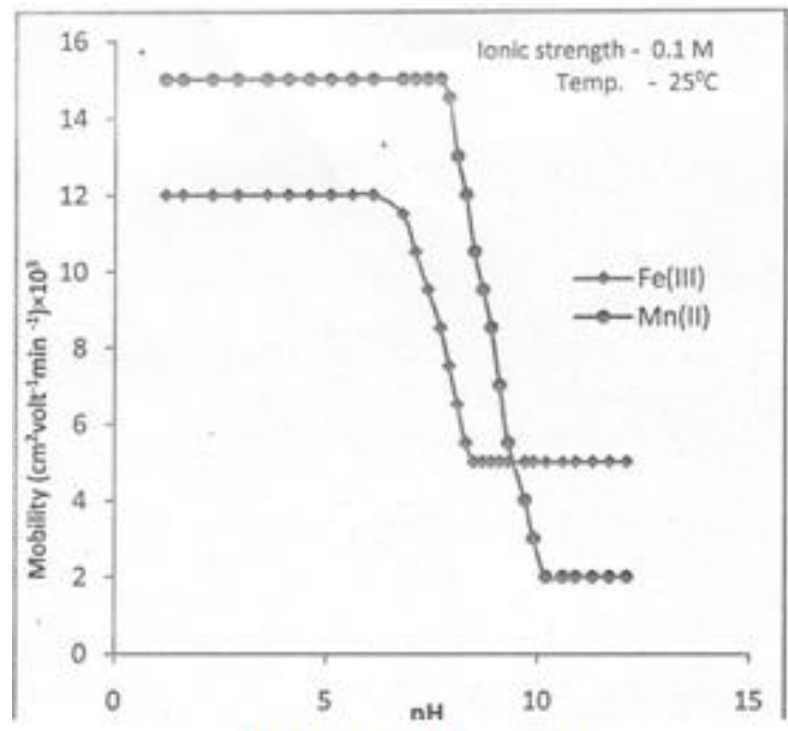

Plot of Mobility vs. pH

Fig1. Mobility curves for M-ephedrine system

The electrophoretic mobility of metal ion spot against $\mathrm{pH}$ gives number of plateaus shown in Fig.1. A plateau is obviously show $\mathrm{pH}$ range where mobility is practically constant. In the region of first plateau metal ions are uncomplexed. It lies in low $\mathrm{pH}$ region where concerned of highly protonated species of ligand is obviously maximum, hence it is concluded that this protonated species of ligand is not complexing. Beyond this $\mathrm{pH}$ range metal ion spot has progressively decreasing mobility. This decrease shows formation of complex of metal ion with ligand. A point is reached beyond which mobility of the metal ion species remain constant. This is the second plateau which corresponds to a $\mathrm{pH}$ region in which 1:1 cationic complex is formed. One ligand anion combines with each metal ion to form $[\mathrm{Fe}(\mathrm{L})]^{++}$and $[\mathrm{Mn}(\mathrm{L})]^{+}$, cationic complexes with $\mathrm{Fe}(\mathrm{III})$ and $\mathrm{Mn}(\mathrm{II})$ respectively. On further increase of $\mathrm{pH}$ beyond the second plateau there is no further decrease in mobility of metal ion indicates no further complexation takes place. It is significant that these studies give clear evidence of the binary complex formation of 1:1 composition. The complexation of metal ions with ligand anion [L] can be represented by equation(3).

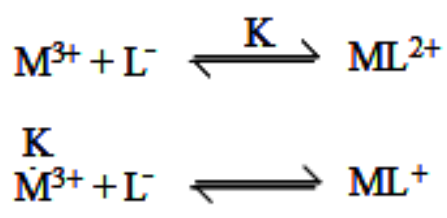

Where $\mathrm{M}^{3+}=\mathrm{Fe}^{3+}$ and $\mathrm{M}^{2+}=\mathrm{Mn}^{2+}$ metal ion, $[\mathrm{L}]=$ ephedrine anion, $\mathrm{K}=$ stability constants.

The spot is moving under the influence of electric field and the overall mobility " $U$ " is given by equation $^{17}$

$$
\mathrm{U}=\sum_{\mathrm{n}} \mathrm{u}_{\mathrm{n}} \mathrm{f}_{\mathrm{n}}
$$

Where, $u_{n}$ and $f_{n}=$ mobilities and mole fractions of particular complex species respectively. The final equation is for different equilibria is represented as: 


$$
\mathrm{U}=\frac{\mathrm{u}_{0}+\mathrm{u}_{1} \mathrm{~K}_{1}\left[\mathrm{~L}^{-}\right]}{1+\mathrm{K}_{1}\left[\mathrm{~L}^{-}\right]}
$$

Where uo and ui are the ionic mobilities of uncomplexed metal ions and 1:1 metal complexes, respectively. For calculating stability constant $\mathrm{K}$, the region between first and second plateau is pertinent. The system contains using the principle of average mobility. Stability constant can be calculated with the help of mobility of first plateau and second plateau the system contains overwhelmingly a mixture of free metal ion and 1:1 complex. Using the principle of average mobility provided.

$$
\begin{aligned}
& \mathrm{U}=\frac{\mathrm{u}_{0}+\mathrm{u}_{1}}{2} \\
& \mathrm{~K}=\frac{1}{\left[\mathrm{~L}^{-}\right]}
\end{aligned}
$$

Accordingly the $\mathrm{pH}$ corresponding to the average value of $\mathrm{u}_{0}$ and $\mathrm{u}_{1}$ is found from the figures and with the knowledge of dissociation constant of ligands, the concentration of ionic ligands at this $\mathrm{pH}$ is calculated. Its reciprocal gives the stability constant $\mathrm{K}$ of the 1:1 complex. The concentration of chelating ligands anion $[\mathrm{L}]$ is determined as:

$$
\left[\mathrm{L}^{-}\right]=\frac{\left[\mathrm{L}_{\mathrm{t}}\right]}{1+\frac{\mathrm{H}^{+}}{\mathrm{k}}}
$$

Where $\left[\mathrm{L}_{\mathrm{t}}\right]=$ total concentration of the ligand ephedrine

$\mathrm{k}=$ dissociation constant of ephedrine.

With the help of dissociation constant of ephedrine $\left(\mathrm{pk}_{\mathrm{a}}=9.958\right)$. The concentration of ephedrine anion is determined for the $\mathrm{pH}$, from which the stability constant $(\mathrm{K})$ is calculated.

\section{Metal-Ephedrine-Nitrilotriacetate Mixed Sysem}

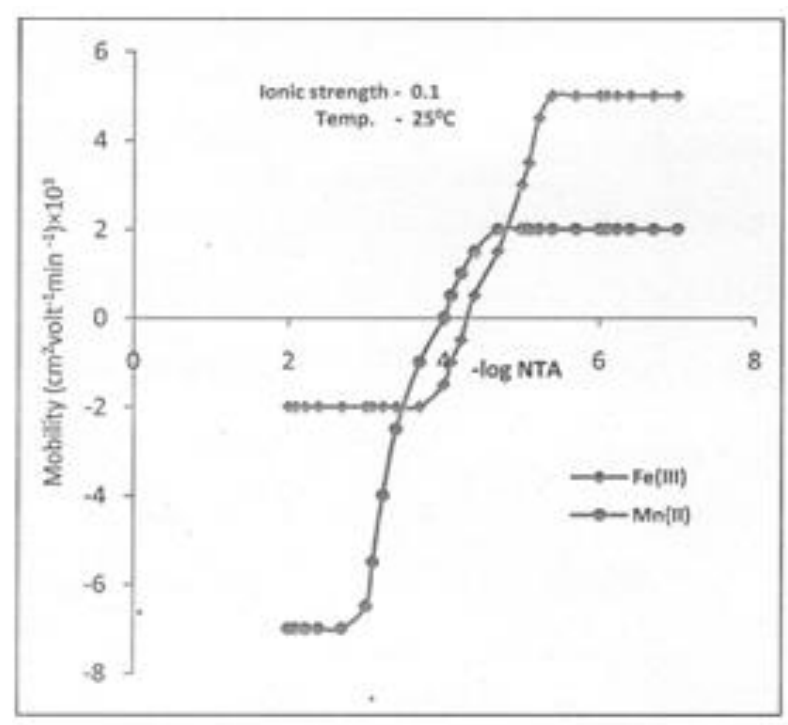

Fig2. Mobility curves for M-ephedrine - NTA system

Fig.2 illustrate the studies carried out in M-ephedrine-NTA mixed complexes. The first plateau corresponds to binary M-ephedrine complexes whereas the second plateau corresponds to the formation of new complex. The first plateau is in agreement with the mobility of the binary metalephedrine complexes. And the mobility of last plateau is more negative than that of the first plateau. Thus it is inferred that the coordination of NTA anion to 1:1 metalephedrine complex resulting in the formation of 1:1:1 metal-ephedrine-NTA mixed complexes as 
$\mathrm{K}^{*}$

$\mathrm{M}-\mathrm{L}+\mathrm{NTA} \rightleftharpoons \mathrm{M}-\mathrm{L}-\mathrm{NTA}$

$\mathrm{U}=\frac{\mathrm{u}_{0}+\mathrm{u}_{1} \mathrm{~K}^{\prime} \mathrm{NTA}}{1+\mathrm{K}^{\prime} \mathrm{NTA}}$

For M-L-NTA complexes the stability constant $\mathrm{K}^{\prime}$ is calculated by using modified equation.

Where, $\mathrm{u}_{0}$ and $\mathrm{u}_{1}$ are the mobilities of M-L and M-L-NTA complexes. From the Fig. 2 concentration of NTA at which overall mobility as the mean of the mobilities of the two plateaus is determined by using the equation. The concentration of NTA anion at $\mathrm{pH} 8.5$ for this NTA concentration is calculated. ' $\mathrm{K}$ ' is obviously equal to $1 /[\mathrm{NTA}]$.

The stability constant values for binary (M-L) and mixed (M-L-NTA) complexes are given in Table: 1 and 2 which follows the Irving William's ${ }^{18}$ order for stability constants of transition metals of the first transition series and no comparison can be made with the literature value due to its unavailability.

Table1. Stability constant of M-ephedrine binary complexes

Temperature $25^{\circ} \mathrm{C}$

Ionic Strength $0.1 \mathrm{M}$

\begin{tabular}{|l|c|c|}
\hline \multirow{2}{*}{ Metal ions } & \multicolumn{2}{|c|}{ Stability constants } \\
\cline { 2 - 3 } & $\begin{array}{c}\text { Calculated values } \\
\log \mathrm{k}\end{array}$ & $\begin{array}{c}\text { Literature values } \\
\log \mathrm{k}\end{array}$ \\
\hline $\mathrm{Fe}(\mathrm{III})$ & 4.2601 & - \\
\hline $\mathrm{Mn}(\mathrm{II})$ & 3.0941 & - \\
\hline
\end{tabular}

Table2. Stability constant of M-ephedrine-NTA mixed complexes

Temperature $25^{\circ} \mathrm{C} \quad$ Ionic Strength $0.1 \mathrm{M}$

\begin{tabular}{|l|c|c|}
\hline \multirow{2}{*}{ Metal ions } & \multicolumn{2}{|c|}{ Stability constants } \\
\cline { 2 - 3 } & $\begin{array}{c}\text { Calculated values } \\
\log \mathrm{k}\end{array}$ & $\begin{array}{c}\text { Literature values } \\
\log \mathrm{k}\end{array}$ \\
\hline $\mathrm{Fe}(\mathrm{III})$ & 4.6990 & - \\
\hline $\mathrm{Mn}(\mathrm{II})$ & 3.3979 & - \\
\hline
\end{tabular}

\section{CONCLUSION}

Metal toxicity is a major problem for human and other living beings. Fe(III) and $\mathrm{Mn}(\mathrm{II})$ are present in many structural and functional part in the human body and essential for normal physiological processes, but they are toxic if present in excess. The chelating agents are substances that have a strong ability to grab onto toxic metals and dislodge from the tissues. It can be concluded from the present study that ephedrine and NTA may be used to reduce the level of these metal ions from human body and other living beings.

\section{REFERENCES}

[1] Janes, D. L. and Margerum,W. M., Inorg. Chem., 1966, 5, 1135.

[2] Beck, M. T., The determination of complex equilibria. Chapter 8, Van Nostrand, New York, 1969

[3] Alimarin, I. P. and Sheleskaya, V. I., Pure Appl. Chem., 1970, 21, 461.

[4] Diaj, G. M., Alanso, R. P. and Esparza, R. M., J. Inorg. Biochem., 1996, 64, 207.

[5] Obaleya, J. A., Nde-aga, J. B. and Balogun, E.A., Aff. J. Sci., 1997, 1, 10-12

[6] Yambe, S. and Koho, J. P., Chem. Abs., Ill, 1989, $219307 z$.

[7] Jokl, V. J., Chromatography, 1964, 14, 74.

[8] Biernet, J., Rocz. Ch'em., 1964, 38, 343.

[9] A.O. Ajibola, Essential Medicinal Chemistry, ShanesonJeresey, 1999, $2^{\text {nd }}$ Edn., 2 b.

[10] Tewari, B. B., Journal of Chromatography A, 2002, 962, 233-237.

[11] Tewari, B. B., J. Mex. Chem. Soc., 2008, 52(3), 219-223.

[12] Tewari B. B., RevistaBolivina De Quimica., 2008, 25(1), 4-9. 
[13] Sachan, S. et al, Croat. Chem. Acta, 2011, 84(4), 461-464.

[14] Singh, P. P. and Kanaujia, S., Chem. Sci. Trans.,2013, 2(3), 1028-1034.

[15] Sharma, S. et al., Orient. J. Chem.,2014, Vol. 30(4), 2011-2015.

[16] Singh, A. and Rai, O. P., Orient. J. Chem., 2014, 30(4), 2059-2063.

[17] Nichol, J. Journal of American Chem. Soc., 1970, 72, 2367.

[18] Irving, H. and Williams, R. J. P., Nature, 1948, 162, 746.

Citation: Arvind Singh et al. "Electrophoretic Study of Binary and Mixed Metal Complexes with Medicinally Important Ligands" International Journal of Advanced Research in Chemical Science (IJARCS), vol. 6, no. 1, pp. 13-18, 2019. http://dx.doi.org/10.20431/2349-0403.0602003

Copyright: (C) 2019 Authors. This is an open-access article distributed under the terms of the Creative Commons Attribution License, which permits unrestricted use, distribution, and reproduction in any medium, provided the original author and source are credited. 